\title{
Further Observations on Visual Perception: The Influence of Pathologies Upon the Absorption of Light and Emission of Bioluminescence
}

\author{
Graham Wilfred Ewing ${ }^{*}, 1$, S.H. Parvez ${ }^{2}$ and I.G. Grakov ${ }^{3}$ \\ ${ }^{I}$ Montague Healthcare, Mulberry House, 6 Vine Farm Close, Cotgrave, Nottingham, NG12 3TU, UK \\ ${ }^{2}$ CNRS Neuroendocrine Unit, Institute Alfred Fessard of Neurosciences, Bât 5, Parc Chateau CNRS, 91190 Gif Sur \\ Yvette, France \\ ${ }^{3}$ MIMEX Inc, 135 Plastunskaya Street, Sochi 354000, Russia
}

\begin{abstract}
The absorption and emission of light by biological systems is a dilemma for the research community which remains transfixed upon the bottom-up systems biology approach. Many health care professionals do not yet accept that photosensitivity is an essential aspect of the body's function.

This article highlights that light is often required to activate enzymes and/or proteins in biological systems. Inadequate levels of exposure to light may be responsible, at least in part, for the uncoiled nature of proteins found in diabetes mellitus, Alzheimer's disease, and other conditions. Moreover the emission of light, the consequence of protein reactions with reactive substrates or of reactive oxygen species, is an often observed characteristic of pathologies and influences the visual perception of colour. It illustrates that a significant diagnostic principle exists by measuring the levels of light absorbed and/or the bioluminescence released from fluorescent pathologies.
\end{abstract}

Keywords: Bioluminescence, colour perception.

\section{INTRODUCTION}

There is not yet any significant level of understanding of the mechanisms which regulate the body's function. We now know that genes produce our proteins and possess our genetic template but we do not yet know how this is regulated. Many genes produce more than one protein however the mechanisms for the production of one or other protein are not yet known.

The recognition that sense perception, and in particular colour perception, is linked to the function of the autonomic nervous system (top-down systems biology) appears to challenge the most fundamental concepts of reductionist biomedical research which focuses upon the symptoms of pathology and excludes any significant consideration of sensory input and the mechanisms which naturally regulate the body's function (bottom-up systems biology).

That colour is linked to the function of all cellular processes has been recognised in plant research since Ott [1] first recognised that the colours blue and red influenced the flow and/or function of chloroplasts (plant photoreceptors) and plant growth. In humans the link between colour vision and autonomic nervous system has been recognised since 1941 [2] e.g. the administration of adrenaline and pilocarpine are accompanied by alterations to colour perception.

*Address correspondence to this author at the Montague Healthcare, Mulberry House, 6 Vine Farm Close, Cotgrave, Nottingham, NG12 3TU, UK; Tel:00-44-115-9890304; Fax:00-44-115-9899826;

E-mails: graham.ewing@montague-diagnostics.co.uk;

graham.ewing@montaguehealthcare.co.uk

\section{THE REGULATORY INFLUENCE OF LIGHT}

The body responds to sensory input through touch, sight, hearing, smell, and taste. It may be essential for life [3]. Inadequate levels of sensory input lead to increased morbidity and mortality. Sensory input influences the autonomic nervous system. The sympathetic and parasympathetic nervous systems are influenced by GPCRs. An estimated $30-70 \%$ of drugs are based upon the function of GPCRs. They are involved in the processing and regulation of data from the external and internal environments. In vision, the opsin family of GPCRs convert light into cellular signals [4]; and in smell, olfactory receptors bind smells and pheromones. GPCRs are also involved in the regulation of behaviour and mood, immune system function, blood pressure and digestive processes. Any direct or indirect influences upon such proteins and their reactive substrates will modify sense perception and in particular visual perception. Alterations to their level, influenced by upstream biochemistries, or suppressed by the prevailing reaction conditions e.g. $\mathrm{pH}$, temperature, plasma viscosity, levels of minerals, cofactors, hormones, neurotransmitters, etc; will influence the rate at which proteins react and, ultimately, visual perception. In addition most drugs and disease(s) are associated with cognitive deficits, often involving colour perception. This associates them with protein function [5].

A good example is that of PDE5 which is influenced by Viagra. The phosphodiesterase 5 enzyme (found in several tissues including (but not solely) the rod and cone photoreceptor cells of the retina) catalyze the hydrolysis of cAMP and cGMP. PDE5 absorbs and degrades cGMP. Sildenafil (Viagra) and other similar drugs inhibit this 
enzyme. Consequently, many people who take Viagra notice a change in the way they perceive green and blue colors, or they see the world with a bluish tinge for several hours. For this reason, (i) pilots are prohibited from taking Viagra within 12 hours of a flight and (ii) policemen are advised to take special care when driving and negotiating their passage at traffic lights if they have recently taken Viagra. Viagra [6] activates or suppresses the processes which alter colour perception. If the latter this should be accompanied by lessened colour contrast in addition to altered colour perception. If the former this is likely to be accompanied by increased visual contrast and the emergence of specific colours in the visual spectrum. Both options are plausible. In the case of Viagra the latter seems more plausible. As this family of phosphodiesterase enzymes are genetically encoded it follows that epigenetic influences may decrease or increase the levels of gene expression and hence influence colour perception. In addition it is worth noting that PDE5 is not solely associated with visual function. It is also found in smooth muscle, lung tissues, the penis/erectile function and has been implicated in processes associated with learning and memory. Such enzymes are not solely devoted to visual transduction.

- PDE6 is light-activated. Suppression of its function by drugs reduces colour perception [7]. Moreover, most PDE5 inhibitors also inhibit PDE6 [8,9]. PDEs are implicated in the etiology of atherosclerosis and cardiovascular disease [10-12].

- $\quad$ cGMP is the substrate for PDE6. Regulation of cGMP levels and of associated reaction conditions such as $\mathrm{pH}$, levels of minerals, etc; is therefore a prerequisite for normal function of transduction in the optic pathways.

- $\quad$ The enzymes PDE5 and PDE6 require divalent metal ions, in particular Zinc, to facilitate their function. Accordingly a zinc deficiency will influence signal transduction in the visual pathways.

- cGMP, which is produced by soluble guanylyl cyclase (sGC) in response to nitric oxide [13] is an important signaling molecule in axonal development.

- $\quad$ Light is a trigger for the delivery of Nitric Oxide [14] and subsequent stimulation of vasodilation. Moreover the therapeutic use of light (near infrared, $890 \mathrm{~nm}$ ) to stimulate vasodilation is a commercial reality (Anodyne Therapy System) approved by the US FDA.

- Chronically altered biochemistry leads to genetic mutations in the phototransduction signaling process/cascade thereby influencing the function of retinal structures and the neurovisual pathways.

- $\quad$ Nitric Oxide plays a distinct role in cardiology [1517].

- The body's function is multi-systemic and complex [18-21].

The role of light upon the body's physiology has been the subject of research for many researchers and has been extensively described in many articles by the author [22-25].

\section{THE INFLUENCE OF LIGHT UPON THE BODY'S PHYSIOLOGY}

Mono-chromatic light influences many of the body's physiological processes. It may be essential for the body's normal and regulated function i.e. without sunlight morbidity and mortality will be significantly enhanced. The precise selection of light and/or colour selects those neurons which are sensitised and part of neurophysiological processes [26]. It influences the function of neurons in the brain and biological processes in the visceral organs e.g.

- $\quad$ it regulates the function of retinal photoreceptors [27]. This use of light has been able to halt brain activity in specific neurons using different colours [28] and influence the firing of neurons.

- it activates the expression of proteins [29] and enhances mitochondrial DNA replication [30].

- $\quad$ it regulates the autonomic nervous system [2,31] and the stability of the physiological systems.

- it regulates Bilirubin metabolism [32,33] and its various isomers.

- $\quad$ it regulates the production of Calcitriol [34,35]. The action of light upon the skin activates processes which produce Calcitriol (Vitamin $\mathrm{D}_{3}$ ). This is involved in neural biochemistries including the synthesis of neurotransmitters, brain detoxification pathways, and has a significant immunomodulatory effect $[36,37]$.

- it activates enzymes, which catalyse the body's function $[38,39]$.

- $\quad$ it influences the production of Nitric Oxide $[13,40]$ and subsequent regulation of blood pressure, lipid peroxidation, blood flow [41] and heart rate [42].

- $\quad$ and many other biological processes including (but not limited to) the migration of stem cells [43]; rate of wound healing [44-46]; rate at which proteins translocate to the cell membrane; function of the lymphatic system [47]; regulation of intercellular $\mathrm{pH}$ balance [48,49]; sperm motility [50] and sexual function [51]; and immune function [52-54], etc.

- the effect of light upon nitric oxide formation may have potential anti-cancer application [55].

There is an immense amount of data which illustrates the therapeutic effect of light including that summarised in articles by the author [21,23,56-59].

Proteins exist in multi-level, multi-energetic states. They require energy to be activated and often release energy as they decay into lower energy states following their reaction.

Some proteins do not fold correctly unless glycosylated. As discussed [60] light plays a significant role activating such proteins and moreover the light emitted may change following the protein reaction. The principle appears increasingly evident. Monochromatic light, received from the environment (and/or generated and transmitted in vivo), raises proteins/enzymes to their activated state. This is not a novel finding and has been reported by many researchers. Nevertheless the understanding that light may be essential 
for their subsequent reaction and can influence differing biochemistries is most significant. The delivery of monochromatic light stimulates specific biochemical processes and regulates the function of the physiological systems [22, 23]. It synchronises the activity of groups of neurons [61] and their electrical impulses [62].

Lower levels of such proteins, arising from reduced genetic expression of proteins and /or the consequence of stress, and less favourable reaction conditions will reduce the number and rate of protein reactions e.g. firefly luciferin is oxidised by the enzyme luciferase in the presence of Magnesium, oxygen and ATP and yields a photon of light. This forms the basis of an assay for ATP however altered biochemical pathways - due to the adverse effects of $\mathrm{pH}$, temperature, levels of minerals (in particular of $\mathrm{Mg}$ ) and viscosity - influence the rate at which reactions proceed and may influence subsequent biochemical outcomes. They may alter the genetic profile and create genetic mutations $[63,64]$.

Many proteins other than GPCRs are visually active. Knowledge of their chemiluminescent properties has been used to develop analogues with greater fluorescence but with the intention of measuring levels of biochemical markers rather than rate of reaction e.g. a bioluminescent assay has been proposed as a general method for the study of protein glycosylation [65]. Moreover the modification of chemical structure will modulate the ability of each biochemical or analogue to absorb light of a particular frequency or colour.

This alone may be considered to be a reasonable explanation for the phenomena of colour perception however such explanation does not adequately explain all known and related phenomena. In particular, the influence of bioluminescence upon colour perception. The ability to diagnose disease from its presymptomatic origins (a feature of Virtual Scanning) indicates that such bioluminescence must be generated by pathologies as a consequence of the light emitted from catalytic enzymes and reactive oxygen species as they decay into lower energy states.

There are numerous observed precedents linking colour perception to disease. One of the most striking precedents is that light is not solely absorbed through the neurovisual channels. It is also absorbed by the skin e.g. in the case of Vitamin D. It is assumed that these are the only two mechanisms for the absorption of light however researchers have established that blue light when applied to the back of the knee alters human circadian rhythm. Subsequent research [66] has indicated that the skin may act as an extra-retinal photoreceptor able to influence circadian rhythm. Light also influences the function of the pineal gland and, like the skin, influences circadian rhythms [67]. The production of melatonin by the pineal gland is stimulated by darkness and inhibited by light [68]. Although there is not yet a clear understanding of the role of the pineal gland (and hence of melatonin and serotonin) it is perceived to rise and fall in response to natural sunlight (during the day and night), and to seasonal fluctuations i.e. it may act to compensate or adjust for different levels of natural sunlight. In addition, different wavelengths are able to penetrate tissue to different depths $[69,70]$ i.e. at sufficient depth to influence the function of visceral organs.
The conventional explanation fails to explain how the number of colour-sensitive retinal cones can differ significantly but that colour perception can be unaltered. This indicates that colour perception is also influenced by our brains, and associated neurovisual pathways, and not solely by our eyes [71]. Similarly, those from tropical regions of the world where light is more intense have inherent genetic traits which are able to compensate for regional variation i.e. our visual perception is context dependent. In addition, the receipt of sensory input alone cannot explain the influence of stress and of the stress response upon the body's physiology. This can only be explained by considering how sensory input is processed by the brain. The neural response to stress is manifest as pathologies and subsequently influences colour perception i.e. the cumulative association of sensory input from the various senses is manifest as a physiological response of differing levels of intensity.

\section{THE INFLUENCE OF PATHOLOGY-RELATED BIOLUMINESCENCE UPON COLOUR PERCEPTION}

The phenomena of bioluminescence is considered to be associated with the excitation of substrates by enzymatic catalysis or by oxidative stress involving reactive oxygen species [72-75].

The evolutionary processes create or adopt physiological phenomena or developments which are passed onwards throughout subsequent generations. From life's origins as plant species, through marine sea life, light has been adapted from its earliest creation of life. The emission of natural bioluminescence is seen in marine life, in deep sea marine species; in fire-flies, glow worms, and insect larvae; and in vertebrates. It would be unusual in the extreme if evolution, in the human, had discarded such a valuable principle.

This emission of bioluminescence may have significant diagnostic potential [76]. Light influences the function of all cellular processes however the absorption of light may be primarily a therapeutic principle i.e. that light of specific frequency(s) stimulates specific biochemistries and systems. Nevertheless the measurement of light absorbed may be used to make diagnostic conclusions. The data presented in this article illustrates the ways in which pathologies influence the primary visual mechanisms and alter colour perception however this may not fully explain all of the aspects of colour perception.

The emission of light from protein-substrate reactions represents a diagnostic principle which, if adapted, may lead to a measure of rate of reaction rather than the diagnosis of the level of a specific biomarker. In principle, this may be a significantly more precise method of diagnosing the progression of disease $[21,23]$. It illustrates that the emission of pathology-related bioluminescence could influence or reduce the light absorbed by the optic mechanism and hence inhibit the perception of colour and colour contrast but it does not explain that the perceived visual intensity of such colours increases with the emergence of pathology.

The body literally glows with energy [77]. Moreover the locations from which light is released differs from the locations from which heat is released thereby illustrating that there may be distinctly different mechanisms. Blood and most body fluids are fluorescent e.g. forensic scientists use 
ultraviolet lights at crime scenes to find blood, urine, or semen.

The principle(s) that light is emitted by protein-substrate reactions is recognised in several precedents e.g.

- BioAstral, part funded by the DTI, a spin-off from the University of Leicester [78].

- $\quad$ Fluorescent light illuminates blood sugar disorders in patients. The Dutch company DiagnOptics has developed a device that may be able to identify diabetes risk simply by shining a fluorescent light on a patch of skin below the elbow. The technique illuminates advanced glycation end products [79].

- Increased biophoton emission has been linked to the progression of disease e.g. in multiple sclerosis [80].

- Systemic parameters are linked to diabetic retinopathy [81-87].

Various articles elucidate the link between natural fluorescence, glycation and diabetes [88-92] and in subsequent cardiovascular developments [93-96]. Biophoton emission may be linked to current DM indicators such as HbA1c [97,98]; and the detection of other medical conditions [89] including gastrointestinal disease(s) [99101], cancers [102-107], conditions of unknown origin $[108,109]$, and as an early marker of retinal deterioration $[110,111]$. Albumin is naturally bioluminescent. The glycated form of albumin has been proposed as an alternative to $\mathrm{HbAlc}$ in the measurement of diabetes [112, 113].

The loss of blue-yellow colour vision has been shown to be an indicator of the onset of type 1 diabetes mellitus [112, 114-122]. The loss of other colours in the visual spectrum are associated with coronary heart disease [123], migraine [124-126] and may also be implicated in the diagnosis of other heart conditions [127-129].

Light is partially absorbed and emitted by haemoglobin, albumin and their glycated analogues. Similarly ATP [130132] and other nucleotides [133] may exhibit the same property of being able to weakly absorb and emit light and/or that biologically generated analogues may be fluorescent. Other potentially fluorescent biomarkers include NADH, FAD, tryptophan, collagen, and endogenous porphyrins [134].

\section{DISCUSSION}

The objective of this article is to demonstrate the existence of a significant scientific principle i.e. that the light absorbed by proteins and the bioluminescent released from many protein-substrate reactions can be used diagnostically and is the principle upon which Virtual Scanning is based. The idea of linking visual perception to pathology arose out of Grakov's research re the medical application of industrial lasers [135] conducted at the University of Novosibirsk in the period 1980-2000. This first development, Virtual Scanning, is now being followed by other commercial developments which seek to adapt the absorption and emission spectra of biological phenomena.
Monochromatic light has long been known to activate biological systems [136-138]. (Alexander Gurwitsch, V.P.Kazmacheyev and others established that every living cell emits light). Most proteins are visually active and/or naturally bioluminescent [136,137]. A similar principle appears to be used in non-linear interferometric vibrational imaging [139, 140] which, like Virtual Scanning, has taken many years to be developed.

Proteins react with substrates. Light provides the energy of activation required to energise the protein and/or its substrate into their reactive conformations [138]. In most cases this will release energy as heat however, as outlined in this article, it may also be accompanied by the release of electromagnetic radiation in the IR, Visible and UV spectrum. Moreover, many marine organisms have adapted light in various ways. Some mammals have no colour perception or have vision which preferentially absorbs in the IR or UV.

In some cases the protein may be activated to different energy states by light of different energy/colour. This stimulates different biochemistries and may be accompanied by the release of energy as heat or as light of different wavelengths. Some proteins may be relatively benign i.e. they are not visually active or are only weakly active, however their conversion to analogues may increase their inherent fluorescence. The development of problems re the regulation of blood glucose, which we recognise as diabetic mellitus, leads to a biochemical cascade involving the production of reactive oxygen species which release light according to the energetic states of the functional molecule(s) and glycated, or other, analogues.

Every genetic change will influence the level and structure of proteins expressed and of subsequent biochemical analogues (and their light absorbing or emitting properties).

Moreover the eye is a parabolic photoreceptor. It focuses and amplifies sensori-visual input. Whilst it routinely detects about $10^{\wedge} 9$ photons per second during daylight it also detects the light intensity of specific colours at as low as 50 photons per second [141]. It is a detector of extraordinary flexibility and scope. As outlined, its function is influenced by the release of fluorescence from blood i.e. by the bioluminescence of specific pathologies.

This illustrates that light perform a role which is analogous to that of software for our biochemical hardware. The phenomena is not unique to marine species but may be a necessary requirement for all intercellular commmunication and hence for the regulation and organisation of all forms of life.

\section{ACKNOWLEDGEMENTS}

None declared.

\section{COMPETING INTERESTS}

Graham Wilfred Ewing \& Elena Nikolayevna Ewing (Dr) are Directors of Montague Healthcare, a company dedicated to the future commercialisation of Virtual Scanning. No other organization or person offered any funds to support this work. 


\section{REFERENCES}

[1] Ott JN. Health and Light: The Effects of Natural and Artificial Light on Man and Other Living Things. Self published. *Film: Dancing Flowers, John Ott, 1950s. 1973.

[2] Kravkov SV. Color vision and the autonomic nervous system. J Opt Soc Am 1941; 31: 335-42.

[3] Ferber SG, Makhoul IR. The effect of skin-to-skin contact (kangaroo care) shortly after birth on the neurobehavioral responses of the term newborn: a randomized, controlled trial. Pediatrics 2004; 113: 858-65.

[4] Arshavsky VY, Lamb TD, Pugh Jr EN. G proteins and phototransduction. Annu Rev Physiol 2002; 64: 153-87.

[5] Lloyd MJ, Fraunfelder FW. Drug-induced optic neuropathies. Drugs Today 2007; 43: 827

[6] Luu JK, Chappelow AV, McCulley TJ, Marmor MF. Acute effects of sildenafil on the electroretinogram and multifocal electroretinogram. Am J Ophthalmol 2001; 132: 388-94.

[7] Zhang X, Feng Q, Cote RH. Efficacy and selectivity of phosphodiesterase-targeted drugs to inhibit photoreceptor phosphodiesterase (PDE6) in retinal photoreceptors. Invest Ophthalmol Vis Sci 2005; 46: 3060-6.

[8] Siegel GJ, Albers W. Basic neurochemistry: molecular, cellular and medical aspects. Philadelphia: pub, Lippincott-Raven, 1999; vol. 1.

[9] Cote RH. Characteristics of Photoreceptor PDE (PDE6): similarities and differences to PDE5. Intern J Impotence Res 2004; 16: S28-S33.

[10] Matsumoto T, Kobayashi T, Kamata K. Phosphodiesterases in the Vascular System. J Smooth Muscle Res 2003; 39: 67-86.

[11] Nagaoka T, Shirakawa T, Balon TW, Russell JC, Fujita-Yamaguchi Y. Cyclic nucleotide phosphodiesterase 3 expression in vivo: evidence for tissue-specific expression of phosphodiesterase 3A or 3B mRNA and activity in the aorta and adipose tissue of atherosclerosis-prone insulinresistant rats. Diabetes 1998; 47: 1135-44.

[12] Netherton SJ, Jimmo SL, Palmer D. Altered phosphodiesterase 3mediated cAMP hydrolysis contributes to a hypermotile phenotype in obese JCR: LA-cp rat aortic vascular smooth muscle cells: implications for diabetes-associated cardiovascular disease. Diabetes 2002; 51: 1194-200.

[13] Robert F. Furchgott - Nobel Lecture. 31 Dec 2010. Available at: http://nobelprize.org/nobel_prizes/medicine/laureates/1998/furchgott-le cture.html

[14] Sortino S. Light-controlled nitric oxide delivering molecular assemblies. Chem Soc Rev 2010; 39: 2903-13.

[15] Dessy C, Ferron O. Pathophysiological roles of nitric oxide: in the heart and the coronary vasculature. Curr Med Chem Anti Inflamm Anti Allergy Agents Med Chem 2004; 3: 207-16.

[16] Hayward CS, Kelly RP, MacDonald PS. Inhaled nitric oxide in cardiology practice. Cardiovasc Res 1999; 43: 628-38.

[17] Surks HK. cGMP-dependent protein kinase I and smooth muscle relaxation: a tale of two isoforms. Circ Res 2007; 101: 1078-80.

[18] Ewing GW, Ewing EN. Neuroregulation of the physiological systems by the autonomic nervous system - their relationship to insulin resistance and metabolic syndrome. Biogenic Amines 2008; 22: 208-39.

[19] Ewing GW, Ewing EN, Nwose EU. Virtual Scanning technology - the relationship to oxidative stress and applicability to diabetes management. Biogenic Amines 2008; 22: 195-207.

[20] Ewing GW, Ed. The multi-systemic nature of diabetes mellitus. Presented at $6^{\text {th }}$ World Congress on Prevention of Diabetes and its Complications, Dresden 2010.

[21] Ewing GW, Parvez SH. The Multi-systemic Nature of Diabetes Mellitus: genotype or phenotype? N Am J Med Sci 2010; 2: 444-56.

[22] Ewing GW. A theoretical framework for photosensitivity: evidence of systemic regulation. J Comp Sci Sys Biol 2009; 2: 287-97.

[23] Ewing GW. There is a need for an alternative or modified medical paradigm involving an understanding the nature and significance of the physiological systems. N Am J Med Sci 2010; 2: 1-6.

[24] Ewing GW, Ewing EN, Parvez SH. Developmental dyslexia: the link with the autonomic nervous system and the physiological systems. Biogenic Amines 2009; 23: 115-90.

[25] Ewing GW, Ewing EN, Parvez SH. The multi-systemic origins of migraine. Biogenic Amines 2009; 23: 1-52.

[26] Gerber U. Metabotropic glutamate receptors in vertebrate retina. Doc Ophthalmol 2003; 106: 83-7.

[27] Binder BM, Biernbaum MS, Bownds MD. Light activation of one rhodopsin molecule causes the phosphorylation of hundreds of others. A reaction observed in electropermeabilized frog rod outer segments exposed to dim illumination. J Biol Chem 1990; 265: 15333-40.
[28] Igarashi H, Inomata K. Effects of low-power gallium aluminium arsenide diode laser irradiation on the development of synapses in the neonatal rat hippocampus. Acta Anat 1991; 140: 150-5.

[29] Cruz FG, Koh JT, Link KH. Light-activated gene expression. J Am Chem Soc 2000; 122: 8777-8.

[30] Vacca RA, Marra E, Quagliariello E, Greco M. Activation of mitochondrial DNA replication by He-Ne laser irradiation. Biochem Biophys Res Commun 1993; 195: 704-9.

[31] Ewing GW, Ewing EN. Cognition, the autonomic nervous system and the physiological systems. Biogenic Amines 2008; 22: 85-162.

[32] Cremer RJ, Perryman PW, Richards DH. Influence of light on the hyperbilirubinemia in infants. Lancet 1958; 1: 1094-7.

[33] Sisson T. Visible light therapy of neonatal hyperbilirubinemia. Photochem Photobiol Rev 1976; 1:241-68.

[34] Holick MF. Vitamin D: importance in the prevention of cancers, type 1 diabetes, heart disease, and osteoporosis. Am J Clin Nutr 2004; 79: 36271 .

[35] Holick MF. Vitamin D deficiency. N Eng J Med 2007; 357: 266-81.

[36] Garcion E, Wion-Barbot N, Montero-Menei CN, Berger F, Wion D. New clues about vitamin D functions in the nervous system. Trend Endocrinol Metab 2002; 13: 100-5.

[37] Hayes DP. The protection afforded by vitamin D against low radiation damage. Intern J Low Rad 2008; 5: 368-94.

[38] Levskaya A, Weiner OD, Lim WA, Voigt CA. Spatiotemporal control of cell signaling using a light-switchable protein interaction. Nature 2009; 461: 997-1001.

[39] Amat A, Rigau J, Waynant RW, Ilev IK, Tomas J, Anders JJ. Effect of red and near-infrared laser light on adenosine triphosphate (ATP) in the luciferine-luciferase reaction. J Photochem Photobiol B: Biology 2005; 81: 26-32.

[40] Nagase S, Hirayama A, Ueda A, et al. Light-shielded hemodialysis prevents hypotension and lipid peroxidation by inhibiting nitric oxide production. Clin Chem 2005; 51:2397-8.

[41] Kami T, Yoshimura Y, Nakajima T, Ohshiro T, Fujino T. Effects of low-power diode lasers on flap survival. Ann Plast Surg 1985; 14: 27883.

[42] Schafer A, Kratky KW. The effect of colored illumination on heart rate variability. Forsch Komplementmed 2006; 13: 167-73.

[43] Gasparyan L, Brill G, Makela A. Influence of laser radiation on migration of stem cells. Progress in biomedical optics and imaging 2006; 7: [Note(s): 61400P.1-61400P.6].

[44] Mester E, Jaszsagi-Nagy E. The effect of laser radiation on wound healing and collagen synthesis. Studia Biophysica 1973; 35: 227-30.

[45] Horwitz LR, Burke TJ, Carnegie DH. Augmentation of wound healing using monochromatic infrared energy. Adv Wound Care 1999; 12: 3540.

[46] Reddy GK, Stehno-Bittel L, Enwemeka CS. Laser photo stimulation accelerates wound healing in diabetic rats. Wound Repair Regen 2001; 9: 248-55.

[47] Lievens PC. The effect of I.R. laser irradiation on the vasomotricity of the lymphatic system. Lasers Med Sci 1991; 6: 189-91.

[48] Alexandratou E, Yova D, Handris P, Kletsas D, Loukas S. Human Fibroblasts Altercations induced by low power laser irradiation at the single cell level using confocal microscopy. Photochem Photobiol Sci 2002; 1: 547-52.

[49] Opas M, Dziak E. Intracellular $\mathrm{pH}$ and $\mathrm{pCa}$ measurement. Confocal Microscopy Methods and Protocols 1998; 122: 305-13.

[50] Sato H, Landthaler M, Haina D, Schill WB. The Effects of laser light on sperm motility and velocity in vitro. Andrologia 1984; 16: $23-5$.

[51] Dewan E, Menkin MF, Rock J. Effects of Photic Stimulation on the Human Menstrual Cycle. Photochem Photobiol 1978; 27: 581-5.

[52] Young S, Bolton P, Dyson M, Harvey W, Diamantopoulos C. Macrophage Responsiveness to Light Therapy. Lasers Surg Med 1989; 9: 497-505.

[53] Roberts J. Visible Light Induced Changes in the Immune Response through an Eye-Brain Mechanism. J Photochem Photobiol 1995; 29: 315 .

[54] Yamaguchi N, Tsukamoto Y. The Effects of Semiconductor Laser Irradiation on the Immune Activities of Human Lymphocytes in vitro. Laser Life Sci 1994; 6: 143-9.

[55] Shimomura O, Chalfie M, Tsien R. The Nobel Prize in Chemistry 2008.

[56] Ewing GW, Parvez SH. The Multi-systemic Nature of Diabetes Mellitus: genotype or phenotype? N Am J Med Sci 2010; 2: 444-56. 
[57] Ewing GW, Nwose EU, Ewing EN. Obstructive Sleep Apnea Management with Interactive Computer Technology and Nutrition: Two Case Reports. J Altern Complement Med 2009; 15: 1379-81.

[58] Nwose EU, Ewing GW, Ewing EN. Migraine can be managed with Virtual Scanning: case report. The Open Complement Med J 2009; 1: 16-8.

[59] Vysochin YV, Lukoyanov VV, Yaichnikov IK, et al, 2001. Methodology and Technology of Invigoration of Different Population Orders. In: Consolidated 5 year Research Plan of Physical Training, Sports and Tourism State Committee of the Russian Federation. 2000. English translation available at: http: //www.montaguehealthcare. co.uk/files/Vysochin/Vysochin.pdf

[60] Shami PJ, Moore JO, Gockerman JP, Hathorn JW, Misukonis MA, Weinberg JB. Nitric oxide modulation of the growth and differentiation of freshly isolated acute non-lymphocytic leukemia cells. Leuk Res 1995; 19: 527-33.

[61] Cox RH, Shealy CN, Cady RK, Liss S. Pain reduction and relaxation with brain wave synchronization (photo stimulation). J Neurol Orthop Med Surg 1996; 17: 32-4.

[62] Bower B. Perception may dance to the beat of collective neuronal rhythms. Sci News 1998; 153: 20.

[63] McLaughlin ME, Sandberg MA, Berson EL, Dryia TP. Recessive mutations in the gene encoding the beta-subunit of rod phosphodiesterase in patients with retinitis pigmentosa. Nat Genet 1993; 4: 130-4.

[64] Danciger M, Blaney J, Gao YQ, Heckenlively JR, Jacobson SG, Farber DB. Mutations in the PDE6B gene in autosomal recessive retinitis pigmentosa. Genomics 1995; 30: 1-7.

[65] Zatta PF. A new bioluminescent assay for studies of protein $G$ and protein A binding to IgG and IgM. J Biochem Biophys Meth 1996; 32 : 7-13.

[66] Kawara S, Mydlarski R, Mamelak AJ. Low-dose Ultraviolet B Rays Alter the mRNA Expression of the Circadian Clock Genes in Cultured Human Keratinocytes. J Invest Dermatol 2002; 119: 1220-3

[67] Moore RY, Heller A, Wurtman RJ, Axelrod J. Visual pathway mediating pineal response to environmental light. Science 1967; 155: 220-3.

[68] Axelrod J. The pineal gland. Endeavour 1970; 29: 144-8.

[69] Smith KC, Ed. The Science of Photobiology, $1^{\text {st }}$ ed. Plenum Press 1997.

[70] Mahmood U, Weissleder R. Near-Infrared Optical Imaging of Proteases in Cancer. Mol Cancer Ther 2003; 2: 489-96.

[71] Hofer H, Carroll J, Neitz J, Neitz M, Williams DR. Organization of the human trichromatic cone mosaic. J Neurosci 2005; 25: 9669-79.

[72] Nwose EU, Ewing GW. Computer diagnosis in cardiology: oxidative stress hypothesis. N Am J Med Sci 2009; 1: 220-5.

[73] Ursini F, Barsacchi R, Pelosi G, Benassi A. Oxidative stress in the Rat Heart, Studies on Low-Level Chemiluminescence. J Biolumin Chemilumin 1989; 4: 241-4.

[74] Katoaka Y, Cui YL, Yamagata A, et al. Activity-Dependent Neural Tissue Oxidation Emits Intrinsic Ultraweak Photons. Biochem Biophys Res Commun 2001; 285: 1007-11.

[75] Boveris A, Cadenas E, Reiter R, Filipkowski M, NakaseY, Chance B. Organ chemiluminescence: Noninvasive assay for oxidative radical reactions. Pro Nat Acad Sci USA 1980; 77: 347-51.

[76] Wijk RV, Wijk EP. An introduction to human biophoton emission. Forsch Komplementarmed Klass Naturhejlkd 2005; 12: 77-83.

[77] Available at : http: //www.le.ac.uk/biology/phh4/bioastral/

[78] Kobayashi M, Kikuchi D, Okamura H. Imaging of ultraweak spontaneous photon emission from human body displaying diurnal rhythm. PLoS one 2009; 4: e6256.

[79] Lutgers HL, Graaft R, Links TP, et al. Skin Autofluorescence as a Noninvasive Marker of Vascular Damage in Patients With Type 2 Diabetes. Diab Care 2006; 29: 2954-9.

[80] Cohen S, Popp FA. Biophoton emission of the human body. J Photochem Photobiol B 1997; 40: 187-9.

[81] Gardner TW, Antonetti DA, Barber AJ, et al. Diabetic retinopathy: more than meets the eye. Surv Ophthalmol 2002; 47: S253-62.

[82] Porta M, Grosso A, Veglio F. Hypertensive retinopathy: there's more than meets the eye. J Hypertens 2005; 23: 683-96.

[83] Qiao Q, Keinanen-Kiukaanniemi S, Laara E. The relationship between hemoglobin levels and diabetic retinopathy. J Clin Epidemiol 1997; 50: 153-8.

[84] Koh AHC, Yeo KT. Anaemia - More Than Meets the Eye. Singapore Med J 1998; 39: 222-5.
[85] Aiello LP, Cahill MT, Wong JS. Systemic considerations in the management of diabetic retinopathy. Am J Ophthalmol 2001; 132: 76076.

[86] Chew EY. Diabetic retinopathy and lipid abnormalities. Curr Opin Ophthalmol 1997; 8: 59-62.

[87] Harris A, Ciulla TA, Chung HS, Martin B: Regulation of retinal and optic nerve blood flow. Arch Ophthalmol 1998; 116: 1491-5.

[88] Brownlee M. Lilly Lecture 1993: Glycation and diabetic complications. Diabetes 1994; 43: 836-41.

[89] Beisswenger PJ, Makita Z, Curphey TJ, et al. Formation of immunochemical advanced glycosylation end products precedes and correlates with early manifestations of renal and retinal disease in diabetes. Diabetes 1995; 44: 824-9.

[90] Hartog JW, de Vries AP, Lutgers HL, et al. Accumulation of advanced glycation end products, measured as skin autofluorescence, in renal disease. Ann NY Acad Sci 2005; 1043: 299-307.

[91] Meerwaldt R, Hartog JW, Graaff R, et al. Skin autofluorescence, a measure of cumulative metabolic stress predicts mortality in hemodialysis patients. J Am Soc Nephrol 2005; 16: 3687-93.

[92] Sharp PS, Rainbow S, Mukherjee S. Serum levels of low molecular weight advanced glycation end products in diabetic subjects. Diabet Med 2003; 20: 575-9.

[93] Monnier VM, Vishwanath V, Frank KE, Elmets CA, Dauchot P, Kohn RR. Relation between complications of type I diabetes mellitus and collagen-linked fluorescence. N Engl J Med 1986; 314: 403-8.

[94] Airaksinen KE, Salmela PI, Linnaluoto MK, Ikaheimo MJ, Ahola K, Ryhanen LJ. Diminished arterial elasticity in diabetes: association with fluorescent advanced glycosylation end products in collagen. Cardiovasc Res 1993; 27: 942-5.

[95] Stitt AW, He C, Friedman S, et al. Elevated AGE-modified ApoB in sera of euglycemic, normolipidemic patients with atherosclerosis: relationship to tissue AGEs. Mol Med 1997; 3: 617-27.

[96] Baynes JW, Thorpe SR. Glycoxidation and lipoxidation in atherogenesis. Free Radic Biol Med 2000; 28: 1708-16.

[97] Monnier VM, Bautista O, Kenny D, et al. Skin collagen glycation, glycoxidation, and crosslinking arelower in subjects with long-term intensive versus conventional therapy of type 1 diabetes: relevance of glycated collagen products versus $\mathrm{HbAlc}$ as markers of diabetic complications: DCCT Skin Collagen Ancillary Study Group: Diabetes Control and Complications Trial Diabetes 1999; 48: 870-80.

[98] Hempe JM, Gomez R, McCarter RJ, Chalew SA. High and low hemoglobin glycation phenotypes in type 1 diabetes: a challenge for interpretation of glycemic control. J Diab Compl 2002; 16: 313-20.

[99] Kapadia CR, Cutruzzola WF, O'Brien KM, Stetz ML, Enriquez R, Deckelbaum LI. Laser induced fluorescence spectroscopy of human colonic mucosa. Gastroenterology 1990; 99: 150-7.

[100] Cothren RM, Kortum RR, Sivak MV, Fitzmaurice M, Rava RP. Gastrointestinal tissue diagnosis by laser-induced fluorescence spectroscopy at endoscopy. Endoscopy 1990; 36: 105-11.

[101] Papazoglou TG, Liu WQ, Katsamouris A, Fotakis C. Laser-induced fluorescence detection of cardiovascular atherosclerotic deposits via their natural emission and hypocrellin (HA) probing. J Photochem Photobiol B: Biol 1994; 22: 139-44.

[102] Madhuri S, Vengadesan N, Aruna P, Koteeswaran D, Venkatesan P, Ganesan S. Native fluorescence spectroscopy of blood plasma in the characterization of oral malignancy. Photochem Photobiol 2003; 78: 197-204.

[103] Parmeswaran D, Ganesan S, Nalini R, Aruna P, Veeraganesh V, Alfano RR. Native fluorescence characteristics of normal and malignant epithelial cells of human larynx. Proceeding SPIE 1997; 2979: 759-64.

[104] Ganesan S, Sacks PG, Yang Y, et al. Native fluorescence spectroscopy of normal and malignant epithelial cells. Cancer Biochem Biophys 1998; 16: 365-73.

[105] Alfano RR, Tang GC, Pradhan A, Lam W, Choy DSJ, Opher E. Fluorescence spectra from cancerous and normal human breast and lung tissues. IEEE J Quantum Electron 1987; QE-23: 1806-11.

[106] Mahadevan A, Mitchell MF, Silva E, Thomsan S, Kortum RR. Study of the fluorescence properties of normal and neoplastic human cervical tissues. Lasers Surg Med 1993; 13: 647-55.

[107] Yuanlong Y, Yanming Y, Fuming L, Yuten L, Paozhong M. Characteristic autofluorescence for cancer diagnosis and its origin. Lasers Surg Med 1987; 7: 528-32.

[108] Dorrian CA, Cathcart S, Clausen J, Shapiro D, Dominiczak MH. Factors in human serum interfere with the measurement of advanced glycation end-products. Cell Mol Biol (Noisy-le-grand) 1998; 44: 106979. 
[109] Thomas MC, Tsalamandris C, MacIsaac R, et al. Low-molecularweight AGEs are associated with GFR and anemia in patients with type 2 diabetes. Kidney Int 2004; 66: 1167-72.

[110] Acosta ML, Fletcher EL, Azizoglu S, Foster LE, Farber DB. Early markers of retinal degeneration in $r d / r d$ mice. Mole Vis 2005; 11: 71728

[111] Kurtenbacha A, Schiefera U, Neub A, Zrennera E. Preretinopic changes in the colour vision of juvenile diabetics. Br J Ophthalmol 1999; 83: 436.

[112] Daley ML, Watzke RC, Riddle MC. Early loss of blue-sensitive color vision in patients with type I diabetes. Diab Care 1987; 10: 777-81.

[113] Smith HJ. Rapid test for glycated albumin in Salvia. United States Patent Application 20100167306, 2008.

[114] Inaba M, Okuno S, Kumeda Y, et al. Glycated albumin is a better glycemic indicator than glycated hemoglobin values in hemodialysis patients with diabetes: effect of anemia and erythropoietin injection. $\mathrm{J}$ Am Soc Nephrol 2007; 18: 896-903.

[115] Maar N, Tittl M, Stur M, Zajic B, Reitner A. A new colour vision arrangement test to detect functional changes in diabetic macular oedema. Br J Ophthalmol 2001; 85: 47.

[116] Barton FB, Fong DS, Knatterud GL. Classification of FarnsworthMunsell 100-hue test results in the early treatment of diabetic retinopathy study. Am J Ophthalmol 2004; 138: 119-24.

[117] Davis MD, Fisher MR, Gangnon RE, et al. Risk factors for high-risk proliferative diabetic retinopathy and severe visual loss: Early Treatment Diabetic Retinopathy Study Report \#18. Invest Ophthalmol Vis Sci 1998; 39: 233-52.

[118] Roy MS, McCullough C, Hanna AK, Mortimer C. Colour vision in long standing diabetes mellitus. Br J Ophthalmol 1984; 68: 215.

[119] Hardy KJ, Lipton J, Scase MO, Foster DH, Scarpello JH. Detection of colour vision abnormalities in uncomplicated type 1 diabetic patients with angiographically normal retinas. Br J Ophthalmol 1992; 76: 461.

[120] Ismail GM, Whitaker D. Early detection of changes in visual function in diabetes mellitus. Ophthal Physiol Opt 1998; 18: 3.

[121] Feitosa-Santana C, Paramei GV, Nishi M, Gualtieri M, Costa MF, Ventura DF: Color vision impairment in type 2 diabetes assessed by the D-15d test and the Cambridge Colour Test. Ophthal Physiol Opt 2010; 30: 717-23.

[122] Ong GL, Ripley LG, Newsom RS, Casswell AG. Assessment of Colour vision as a screening test for sight threatening diabetic retinopathy before loss of vision. Br J Ophthalmol 2003; 87: 747-52.

[123] Erb C, Voelker W, Adler M, Wohlrab M, Zrenner E. Color-vision disturbances in patients with coronary artery disease. Col Res Appl 2009; 26: S288-291.

[124] De Marinis M, Rinalduzzi S. Impairment in Colour Perception in Migraine with and Without Aura. Headache 2007; 47: 895-904.

[125] Chronicle E, Wilkins AJ. Colour and visual discomfort in migraineurs. Lancet 1991; 338: 890
[126] Ewing GW, Ewing EN, Parvez SH. The Multi-systemic Origins of Migraine. Biogenic Amines 2009; 23: 1-52.

[127] Vogels RLC, Scheltens P, Schroeder-Tanka JM, Weinstein HC. Cognitive impairment in heart failure: A systematic review of the literature. Eur J Heart Fail 2007; 9: 440-9.

[128] Riegel B, Bennett JA, Davis A, et al. Cognitive Impairment in Heart Failure: Issues of Measurement and Etiology. Am J Crit Care 2002; 11: 520-8.

[129] Staniforth AD, Kinnear WJM, Cowley AJ. Cognitive impairment in heart failure with Cheyne-Stokes respiration. Heart 2001; 85: 18-22.

[130] Leonard NJ. Etheno-bridged nucleotides in enzyme reactions and protein binding. Chemtracts Biochem Mol Biol 1993; 4: 251-84.

[131] Jameson DM, Eccleston JF. Fluorescent nucleotide analogs: synthesis and applications. Meth Enzymol 1997; 278: 363-90.

[132] Hiratsuka T, Uchida K. Preparation and properties of 2' (or 3')-O(2,4,6-trinitrophenyl) adenosine 5'-triphosphate, an analog of adenosine triphosphate. Biochim Biophys Acta 1973; 320: 635-47.

[133] Hiratsuka T. Fluorescent and colored trinitrophenylated analogs of ATP and GTP. Eur J Biochem 2003; 270: 3479-85.

[134] Profio AE. Laser exfluorescence of hematoporphyrin derivative for diagnosis of cancer. IEEE J Quantum Electron 1984; QE-20: 1502-07.

[135] Grakov IG. Strannik diagnostic and treatment system: a virtual scanner for the health service. Minutes of Meeting No. 11 of the Praesidium of the Siberian of the Academy of Medical Sciences of the USSR (AMN) held in Novosibirsk 4 December 1985.

[136] Martinek K, Berezin I. Artificial Light-Sensitive Enzymatic Systems as Chemical Amplifiers of Weak Light Signals. Photochem Photobiol 1979; 29: 637-49.

[137] Hug D H, O'Donnell PS, Hunter JK. Light activation of enzymes. Photochem Photobiol 1980; 32: 841-8.

[138] Yousuf Azeemi ST, Raza SM, Yasinzai M. Colors as Catalysts in Enzymatic Reactions. J Acupunct Meridian Stud 2008; 1: 139- 42.

[139] Bredfeldt JS, Marks DL, Hambir S, Dlott D, Boppart SA, Eds. Nonlinear interferometric vibrational imaging, presented at the Conference on Lasers and Electro-Optics/Quantum Electronics and Laser Science Conference, and published in the Technical Digest (Optical Society of America, 2003), paper CMU4.

http: //www.opticsinfobase.org/abstract.cfm?URI=CLEO-2003-CMU4

[140] Chowdary PD, Jiang Z, Chaney EJ, et al. Molecular Histopathology by Spectrally Reconstructed Nonlinear Interferometric Vibrational Imaging. Cancer Res 2010; 70: 1-8.

[141] Brunner N, De Balthazar C, Alvarez R, Minar J (2008). Detection of weak optical signals by the human visual system : Perspect Neurosci Quantum Phys 2008; Available from: http://home.etu.unige. ch/ alvarra0/Roberto_ALVAREZs_Personal_Page/About_Me_files/E ye_project.pdf 